\title{
Metal Ammine Formation in Solution. XX. On the Formation of Hydroxo Complexes in the Copper(II)-Methylamine System
}

\author{
BADRI VISHAL AGARWALA,* LILIANA ILCHEVA** and JANNIK BJERRUM
}

Chemistry Department I, Inorgartic Chemistry, H. C. Ørsted Institute, University of Copenhagen, DK-2100 Copenhagen Ø, Denmark

This paper reports a spectrophotometric study of the copper(II)-methylamine system in $1 \mathrm{M}$ perchlorate solutions. There is a considerable UVabsorption and the absorption maximum at 328 $\mathrm{nm}$ in solutions which are close to being saturated with basic salt is identified as being caused by the tetrakis(methylamine)di- $\mu$-hydroxodicopper(II) complex. Copper(II)-methylamine solutions stabilized with a sufficient excess of methylamine and made more basic with sodium hydroxide are shown by analysis of the visible spectra to contain the hydroxotetrakis(methylamine)copper(II) complex and the following constants were determined $\left(1 \mathrm{M}(\mathrm{Na}) \mathrm{ClO}_{4}, \sim 23^{\circ} \mathrm{C}\right): K_{5} \cong 0.15$ for the uptake of the 5 th amine molecule by the tetra-amine ion, $K_{4, \mathrm{OH}} \cong 16$ for the uptake of a hydroxide ion by the tetra-amine ion, and $K_{5, \mathrm{OH}} \cong 110$ for the uptake of a hydroxide ion by the penta-amine ion with liberation of an amine molecule.

The copper(II)-methylamine system shows great similarity to the analogous ammonia system. ${ }^{1}$ The four stability constants for the tetrakis(methylamine)copper(II) ion have previously been determined in $2 \mathrm{M}$ methylammonium nitrate. ${ }^{2}$ The present paper describes a spectrophotometric study of the formation, in $1 \mathrm{M}$ perchlorate solutions, of the tetrakis(methylamine)di- $\mu$-hydroxodicopper(II) complex at low methylamine concentrations and of hydroxotetrakis(methylamine)- and pentakis-

\footnotetext{
* On leave on a Danida Fellowship 1978 - 1979 from Department of Chemistry, University of Allahabad, Allahabad 211002, India.

** On leave on a Danida Fellowship 1974-1975 from Chemico-Technological Institute, Analytical Chemistry Department, Sofia 56, Bulgaria.
}

(methylamine)copper(II) complexes at high methylamine concentrations. The diol complex has an absorption maximum at $328 \mathrm{~nm}$. Preparation of the monohydrate of the diol sulphate has been reported by Iitaka et al., ${ }^{3}$ who also confirmed its structure.

At high methylamine concentrations the tetrakisand pentakis(methylamine) ions together with the hydroxotetrakis(methylamine) ion are the dominating complexes and, as in the analogous ammonia system, the visible spectra could be described by the equilibria (1)-(3).

$$
\begin{aligned}
& \mathrm{Cu} \mathrm{am} \mathrm{H}_{2} \mathrm{H}^{2+}+\mathrm{am} \rightleftarrows \mathrm{Cu} \mathrm{am}_{5}^{2+}+\mathrm{H}_{2} \mathrm{O} \\
& \mathrm{Cu} \mathrm{am}{ }_{4} \mathrm{H}_{2} \mathrm{O}^{2+}+\mathrm{OH}^{-} \rightleftarrows \mathrm{Cu} \mathrm{am}_{4} \mathrm{OH}^{+}+\mathrm{H}_{2} \mathrm{O} \\
& \mathrm{Cu} \mathrm{am}_{5}^{2+}+\mathrm{OH}^{-} \rightleftarrows \mathrm{Cu} \mathrm{am}_{4} \mathrm{OH}^{+}+\mathrm{am}
\end{aligned}
$$

\section{EXPERIMENTAL}

Reagents and solutions. The reagents were of analytical grade. The methylamine used was a $40 \%$ aqueous solution from Fluka. The purity was controlled by chromatographic analysis. The content of dimethylamine was found to be less than $1 \%$. The various solutions were prepared in volumetric flasks by weighing, pipetting or titrating from stock solutions. Carbon dioxide-free sodium hydroxide was prepared from a stock solution of saturated $\mathrm{NaOH}$ (so-called Sørensen lye).

Spectrophotometric measurements (UV and Vis) were performed (together with Ilcheva) using a Cary 14 spectrophotometer with a thermostatted $\left(25^{\circ} \mathrm{C}\right)$ cell compartment and (together with Agarwala) using a Cary 118 spectrophotometer at room temperature $\left(22-24^{\circ} \mathrm{C}\right)$. Cells of pathlength 0.1 to 
Table 1. Composition of measured copper(II)-methylamine perchlorate solutions. $\left[\mathrm{OH}^{-}\right]^{\prime}$ is calculated with $K_{\mathrm{am}}=10^{-3}$, and $\left[\mathrm{OH}^{-}\right]^{\prime \prime}$ with $K_{\mathrm{am}}=0.5 \times 10^{-3}$.

\begin{tabular}{rlllllll}
\hline No. & $C_{\mathrm{Cu}}$ & $C_{\mathrm{amH}^{+}}$ & $C_{\mathrm{am}}$ & {$[\mathrm{am}]$} & $C_{\mathrm{NaOH}}$ & {$\left[\mathrm{OH}^{-}\right]^{\prime}$} & {$\left[\mathrm{OH}^{-}\right]^{\prime \prime}$} \\
\hline 1 & 0.00982 & 1.00 & 0.345 & 0.306 & 0 & 0.00030 & \\
2 & 0.00982 & 0.10 & 0.345 & 0.306 & 0 & 0.0030 & \\
3 & 0.00295 & 1.00 & 0.315 & 0.303 & 0 & 0.00030 & \\
4 & 0.00295 & 0.10 & 0.315 & 0.303 & 0 & 0.0030 & \\
5 & & & & & & & \\
6 & 0.01964 & 0.30 & 0.115 & 0.037 & 0 & 0.0010 & \\
& 0.01964 & 0.30 & 0.385 & 0.306 & 0 & 0.0010 & \\
7 & 0.00982 & 1.00 & 2.30 & 2.26 & 0 & 0.0023 & 0.0012 \\
8 & 0.09982 & 0.10 & 2.30 & 2.26 & 0 & 0.019 & 0.010 \\
9 & 0.00982 & 0 & 2.30 & 2.26 & 0.040 & 0.071 & 0.059 \\
10 & 0.00982 & 0 & 2.30 & 2.26 & 0.200 & 0.211 & 0.205 \\
11 & 0.00982 & 0 & 2.30 & 2.26 & 0.40 & 0.406 & 0.403 \\
12 & 0.00982 & 0 & 2.30 & 2.26 & 2.00 & & \\
& & & & & & & \\
13 & 0.00982 & 1.00 & 5.76 & 5.72 & 0 & 0.006 & 0.003 \\
14 & 0.00982 & 0.10 & 5.76 & 5.72 & 0 & 0.041 & 0.023 \\
15 & 0.00982 & 0 & 5.76 & 5.72 & 0 & 0.076 & 0.053 \\
16 & 0.00982 & 0 & 5.76 & 5.72 & 0.120 & 0.157 & 0.140 \\
17 & 0.00982 & 0 & 5.76 & 5.72 & 2.00 & & \\
18 & 0.00982 & 1.00 & 3.46 & 3.42 & 0 & 0.0034 & 0.0017 \\
\hline
\end{tabular}

$5 \mathrm{~cm}$ were used, the reference cells being filled with the copper-free methylamine salt medium.

$\mathrm{pH}$-Measurements were made as described in previous papers. ${ }^{1,2}$

Discussion of the spectrophotometric measurements. The composition of eighteen copper(II) methylamine solutions used in the present work are tabulated in Table 1. With the exception of Nos. 12 and 17 , the solutions are 1 molar with respect to $\left[\mathrm{ClO}_{4}^{-}\right]+\left[\mathrm{OH}^{-}\right]$. As well as the stoichiometric molar concentrations of copper(II) perchlorate, methylamine, methylammonium perchlorate, sodium hydroxide and sodium perchlorate, the table also shows the concentrations of free methylamine $[\mathrm{am}] \cong C_{\mathrm{am}}-4 C_{\mathrm{Cu}}$. The concentration of hydroxide ions is calculated assuming values for the base constant for methylamine $K_{\mathrm{am}}$ of $10^{-3}$ or $0.5 \times 10^{-3}$. The former value is calculated from the acid dissociation constant of the methylammonium ion $\left(K_{\mathrm{amH}^{+}}=10^{-10.77} \text { in } 1 \mathrm{M} \mathrm{CH}_{3} \mathrm{NH}_{3} \mathrm{NO}_{3} \text { at } 25^{\circ} \mathrm{C}\right)^{4}$ and the ionic product of water $\left(K_{\mathrm{w}}=10^{-13.77}\right.$ in $1 \mathrm{M} \mathrm{NaClO}_{4}$ at $\left.25^{\circ} \mathrm{C}\right)^{5}$ the other value $K_{\text {am }}=$ $0.5 \times 10^{-3}$, is tentatively chosen as a possible value for the base constant in the stronger methylamine solutions.
The measurements in the $U V$ region. Fig. 1 shows plots of the absorbance A per cm pathlength versus the wavelength from 300 to $400 \mathrm{~nm}$, and the four parts of the figure show how the band at $328 \mathrm{~nm}$ ascribed to the tetrakis(methylamine)diol complex, $\mathrm{am}_{4}(\mathrm{OH})_{2} \mathrm{Cu}_{2}{ }^{2+}$, changes with the methylamine, methylammonium and copper(II) concentrations. The numbers on the curves refer to the solutions tabulated in Table 1 . The band at $328 \mathrm{~nm}$ can be seen directly for solutions $1-4$ in Fig. 1(a) with $[\mathrm{am}]=0.30 \mathrm{M}$, and for solutions 5 and 6 in Fig. 1 (b), and it is apparent that the band becomes more dominant with decreasing methylammonium-, increasing copper(II)-, and decreasing methylamine concentrations. Solution 5 with [am] $=0.04$ is close to being saturated with basic salt and has $\varepsilon_{\max }=$ $A / C_{\mathrm{Cu}_{u}} \sim 500$ at $328 \mathrm{~nm}$. It was shown that for this solution the absorbance is practically unchanged after $24 \mathrm{~h}$. In Fig. 1(c) with $[\mathrm{am}]=2.26 \mathrm{M}$, the shoulder at $328 \mathrm{~nm}$ is still visible for solution 8 with $\left[\mathrm{amH}^{+}\right]=0.10 \mathrm{M}$, but can no longer be seen for solution 7 with $\left[\mathrm{amH}^{+}\right]=1.00 \mathrm{M}$ or for the strong basic solutions 11 and 12 , where monomeric hydroxoamine complexes are dominant. Only qualitative information can be drawn from the spectra in Fig. 1 concerning the diol formation. This is due 


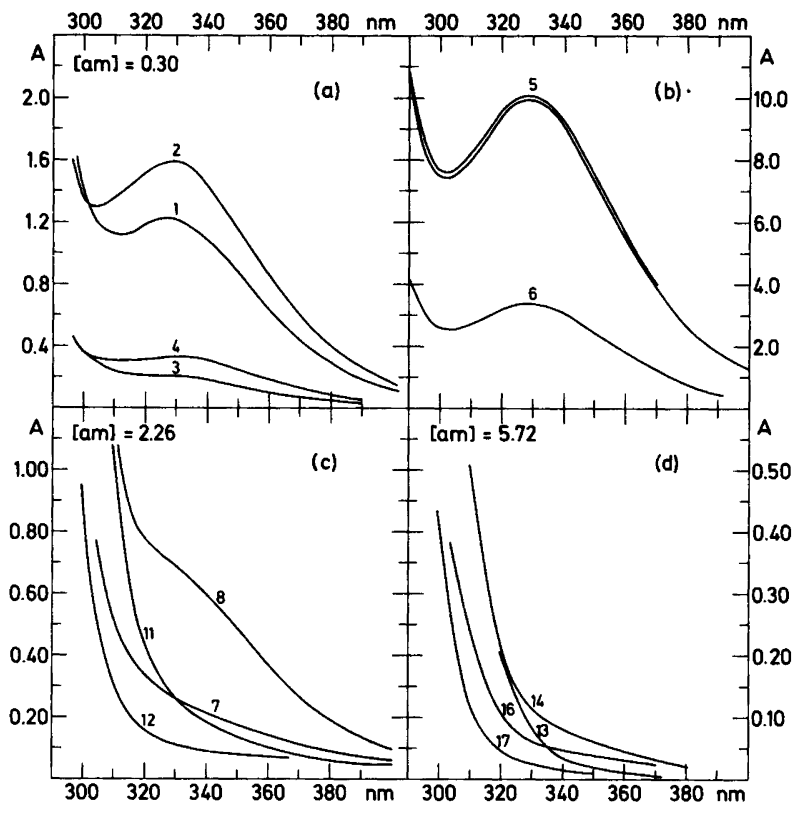

Fig. 1. Absorption curves in UV for copper(II) - methylamine perchlorate solutions arranged in four parts (a) -(d). The absorbance $A=\varepsilon \times C_{\mathrm{Cu}} \mathrm{cm}^{-1}$ is plotted versus the wavelength, and the number on the curves refers to the solutions in Table 1 . Of the two closely situated curves for solution 5 in Fig. 1(b) the lower is measured after about $1 \mathrm{~h}$ and the other after $24 \mathrm{~h}$.

to the strong background absorption from other complexes. This background absorption was insignificant in the analogous ammine system ${ }^{1}$ where the absorbance at $317 \mathrm{~nm}$ was close to being proportional to the concentration of the diol so that the invariability of the constant

$\beta_{2,2}^{\prime}=\frac{A_{317}\left[\mathrm{NH}_{4}\right]^{2}}{C_{\mathrm{Cu}^{2} \alpha_{2}{ }^{2}\left(1-\alpha_{\mathrm{OH}}\right)^{2}\left[\mathrm{NH}_{3}\right]^{2}}}$

could verify the existence of the diol complex. ${ }^{1} \alpha_{2}$ is the fraction of the total aqua ammine copper(II) concentration present as aqua diammine and $\alpha_{\mathrm{OH}}$ the fraction of hydroxide ions bound per copper atom. $\alpha_{\mathrm{OH}}$ was not determined in the methylamine system. However, the relatively small influence of a ten-fold variation of the methylammonium concentration on the absorbance of the solution with $[\mathrm{am}]=0.30 \mathrm{M}$ (Fig. 1(a)) could indicate that the diol is a rather dominant complex in these solutions with $\varepsilon_{\max }=A / C_{\mathrm{Cu}} \sim 500$. Solutions with [am] $>2 \mathrm{M}$, such as solutions 7 and 8 in Fig. 1(c), contain much less of the diol complex. For these solutions the absorbance at $328 \mathrm{~nm}$ increases about three times for a ten-fold decrease of the methylammonium concentration from 1 to $0.1 \mathrm{M}$, but a tentative correction for the background absorption could easily increase this factor to more than ten. The pentakis(amine) complex has a considerably lower absorption in the UV than the tetrakis(amine) complex. This, together with the decreasing concentration of the highly absorbing diol with the increasing amine concentration, explains why the UV absorption for the solutions with $[\mathrm{am}]=5.72 \mathrm{M}$ in Fig. 1(d) are considerably smaller than for the corresponding solutions with $[\mathrm{am}]=2.26 \mathrm{M}$ (Fig. 1(c)). However, at both amine concentrations the concentration of the diol is negligible relative to that of the other complexes and has no disturbing influence on the spectra in the visible region.

Estimation of equilibrium constants from the spectra in the visible region. Figs. 2(a) and (b) show the spectra in the visible region for the two series of solutions arranged according to increasing hydroxide ion concentration at methylamine concentration of $2.26 \mathrm{M}$ (Table 1, Nos. 7-12) and 5.72 $M$ (Table 1, Nos. 13-17), respectively. At these two amine concentrations it is assumed that the spectral 


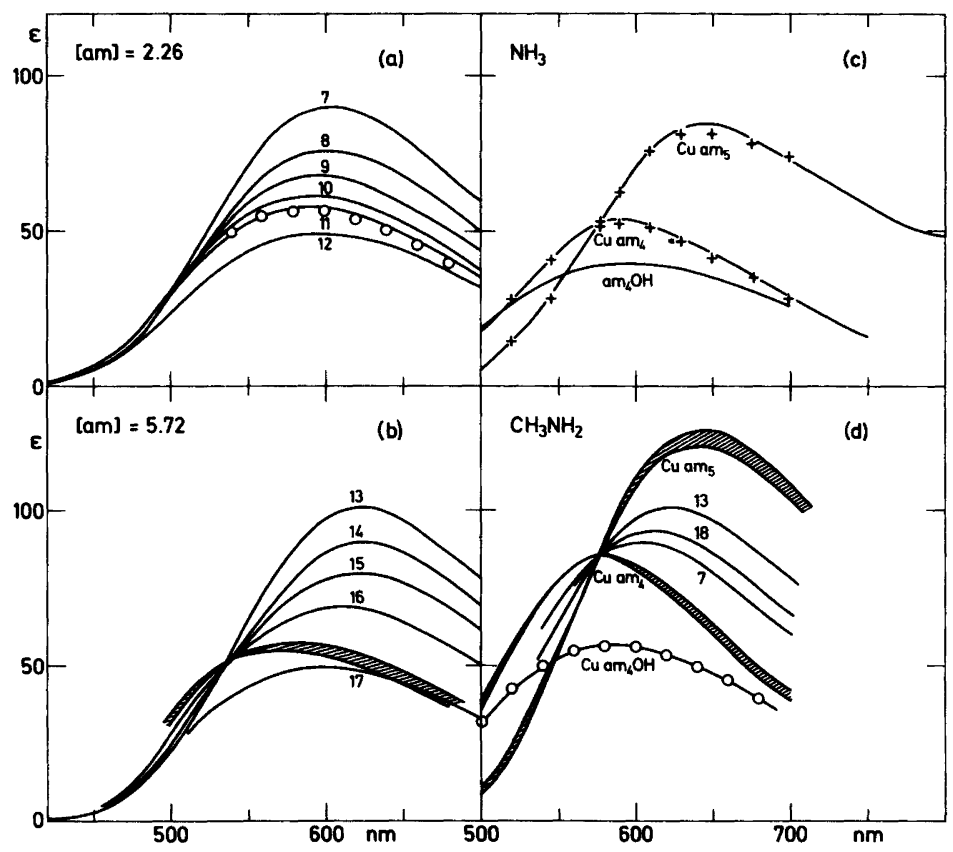

Fig. 2. Absorption curves in the visible region arranged in four parts (a)-(d). The molar extinction coefficient $\varepsilon$ is plotted versus the wavelength, and the numbers on the curves in Figs. 2(a) and 2(b) refer to the solutions in Table 1. The curve for the hydroxotetrakis(methylamine) copper(II) ion in Fig. 2(a) (indicated by circles) and calculated with $K_{\mathrm{OH}}^{\prime} 18.8$ (see Table 2) is also shown in Fig. 2(d). The much higher uncertainty on the same curve in Fig. 2(b), when calculated from the data with [am] $=5.72 \mathrm{M}$ (Table 3), is indicated by the hatched area. The estimated spectra for the tetrakis(methylamine) and pentakis(methylamine) ions in $1 \mathrm{M} \mathrm{CH}_{3} \mathrm{NH}_{3} \mathrm{ClO}_{4}$ calculated on the basis of the curves 7 and 13 are shown in Fig. 2(d). The hatched areas indicate the results of calculations with the penta-amine constant $K_{5}$ varying from 0.15 to $0.20 \mathrm{M}^{-1}$. In Fig. 2(c) the spectra for the corresponding copper(II) ammonia complexes in $2 \mathrm{M}$ $\mathrm{NH}_{4} \mathrm{NO}_{3},{ }^{9}$ and for the hydroxotetrammine copper(II) complex are given for comparison. ${ }^{1}$ The + points indicate values for the tetrammine and pentammine ions in dilute aqueous solution. ${ }^{10}$

change is due to the uptake of a hydroxide ion by the tetrakis(amine)-pentakis(amine) equilibrium mixture. It can be seen that there are isosbestic points for the solutions $8,9,10$ with $[\mathrm{am}]=2.26 \mathrm{M}$ and for the solutions $14,15,16$ with $[\mathrm{am}]=5.72 \mathrm{M}$. At first glance it is unexpected that curves for solutions 7 and 13 with $1 \mathrm{M} \mathrm{CH}_{3} \mathrm{NH}_{3} \mathrm{ClO}_{4}$ do not pass through the isosbestic points. However, this is merely a medium effect. For the other solutions the medium is close to being $1 \mathrm{M}\left(\mathrm{NaClO}_{4}\right)$ with addition of either $0.1 \mathrm{M} \mathrm{CH}_{3} \mathrm{NH}_{3} \mathrm{ClO}_{4}$ or $\mathrm{NaOH}$ up to $0.2 \mathrm{M}$. It has been confirmed by several experiments that the molar extinction coefficients are 5 to $8 \%$ higher in $1 \mathrm{M} \mathrm{CH}_{3} \mathrm{NH}_{3} \mathrm{ClO}_{4}$ than in $1 \mathrm{M} \mathrm{NaClO}_{4}$ and a still greater influence of butylammonium nitrate has previously ${ }^{4}$ been observed in the
copper(II) - butylamine system. At both amine concentrations only three spectra are therefore available for a calculation of the apparent formation constant:

$$
K_{\mathrm{OH}}^{\prime}=\frac{\left[\mathrm{Cu} \mathrm{am} \mathrm{OH}^{+}\right]}{\left(C_{\mathrm{Cu}}-\left[\mathrm{Cu} \mathrm{am} \mathrm{OH}^{+}\right]\right)\left[\mathrm{OH}^{-}\right]}
$$

The calculation is made by means of the general expression:

$$
\frac{[\mathrm{L}]_{\mathrm{z}}-[\mathrm{L}]_{\mathrm{y}}+\left([\mathrm{L}]_{\mathrm{x}}[\mathrm{L}]_{\mathrm{z}}-[\mathrm{L}]_{\mathrm{x}}[\mathrm{L}]_{\mathrm{y}}\right) K_{\text {ass }}}{[\mathrm{L}]_{\mathrm{z}}-[\mathrm{L}]_{\mathrm{x}}+\left([\mathrm{L}]_{\mathrm{y}}[\mathrm{L}]_{\mathrm{z}}-[\mathrm{L}]_{\mathrm{x}}[\mathrm{L}]_{\mathrm{y}}\right) K_{\text {ass }}}=\frac{\alpha_{\mathrm{z}}-\alpha_{\mathrm{y}}}{\alpha_{\mathrm{z}}-\alpha_{\mathrm{x}}}(5)
$$

In this expression $\alpha_{\mathrm{x}}<\alpha_{\mathrm{y}}<\alpha_{\mathrm{z}}$ indicate the fractions of the association product $\left([\mathrm{ML}] / C_{\mathrm{M}}\right)$ in the par- 
Table 2. Estimation of $K_{\mathrm{OH}}^{\prime}$ by use of the molar extinction coefficients of three solutions with $\left[\mathrm{CH}_{3} \mathrm{NH}_{2}\right]=$ $2.26 \mathrm{M}$ and an isosbestic point at $515 \mathrm{~nm}$ (see Fig. $2(\mathrm{a})) .\left(\alpha_{z}-\alpha_{y}\right) /\left(\alpha_{z}-\alpha_{\mathrm{x}}\right)=1 / 2.37=0.422 . K_{\mathrm{OH}}^{\prime}=18.9$ with $K_{\mathrm{am}}=10^{-3}$, and 18.6 with $K_{\mathrm{am}}=0.5 \times 10^{-3}$.

\begin{tabular}{lcccccccc}
\hline No. & 560 & 580 & 600 & 620 & 640 & 660 & 680 & Av. \\
\hline $8(x)$ & 67.2 & 73.4 & 75.4 & 74.3 & 70.3 & 64.5 & 57.5 & \\
& 5.1 & 7.2 & 8.2 & 9.1 & 9.1 & 8.5 & 7.5 & \\
& $(1.2)$ & $(1.3)$ & $(1.3)$ & $(1.5)$ & $(1.5)$ & $(1.4)$ & $(1.3)$ & 1.37 \\
$9(y)$ & 62.1 & 66.2 & 67.2 & 65.2 & 61.2 & 56.0 & 50.0 & \\
& 4.1 & 5.6 & 6.1 & 6.2 & 6.2 & 5.9 & 5.7 & \\
& $(1)$ & $(1)$ & $(1)$ & $(1)$ & $(1)$ & $(1)$ & $(1)$ & 1.00 \\
$10(z)$ & 58.0 & 60.6 & 61.1 & 59.0 & 55.0 & 50.1 & 44.3 & \\
\hline
\end{tabular}

ticular solutions, and $[\mathrm{L}]_{\mathrm{x}}<[\mathrm{L}]_{\mathrm{y}}<[\mathrm{L}]_{\mathrm{z}}$ the free ligand concentrations $[\mathrm{L}]$ in an association reaction: $\mathrm{M}+\mathrm{L} \rightleftarrows \mathrm{ML}$. Numerical values of $\left(\alpha_{\mathrm{z}}-\alpha_{\mathrm{y}}\right) /$ $\left(\alpha_{z}-\alpha_{x}\right)=\left(\varepsilon_{z}-\varepsilon_{y}\right) /\left(\varepsilon_{z}-\varepsilon_{x}\right)$ are obtained from the spectra with an isosbestic point (cf. Tables 2 and 3 ). The expression (5) itself is easily derived by inserting in $\left(\alpha_{z}-\alpha_{y}\right) /\left(\alpha_{z}-\alpha_{y}\right)$ expressions for $\alpha_{x}, \alpha_{y}, \alpha_{z}$ obtained from the three mass action equations. In our case [L] is to be replaced by $\left[\mathrm{OH}^{-}\right]$and $K_{\text {ass }}$ by $K_{\mathrm{OH}}^{\prime}$. The calculation of $K_{\mathrm{OH}}^{\prime}$ was performed with both sets of hydroxide ion concentrations in Table 1 (calculated with $K_{\mathrm{am}}=10^{-3}$ and $0.5 \times 10^{-3}$, respectively) and the results are shown in Tables 2 and 3. Owing to the uncertainty in the hydroxide concentrations the values obtained for $K_{\mathrm{OH}}^{\prime}$, especially at the highest amine concentration, are rather uncertain. A tentative calculation of the constants $K_{5}, K_{4, \mathrm{OH}}$ and $K_{5, \mathrm{OH}}$ [corresponding to equations (1)-(3)], analogous to those in the preceding paper, ${ }^{1}$ using the average values found for $K_{\mathrm{OH}}^{\prime}$
(18.8 and 14.7, respectively, at the two amine concentrations) gave values of $K_{5}=0.14, K_{4, \mathrm{OH}}=15.6$ and $K_{5, \mathrm{OH}}=112$. This estimate is rather uncertain, but is supported by a direct determination of $K_{5}$, for the pentammine complex in strong methylamine-methylammonium solutions, for which hydroxo complex formation can be neglected. In the expression for the pentammine constant, eqn. (6),

$K_{5}=\frac{K_{4, \mathrm{OH}}}{K_{5, \mathrm{OH}}}=\frac{\left[\mathrm{Cu} \mathrm{am}_{5}{ }^{2+}\right]}{\left[\mathrm{Cu} \mathrm{am}{ }^{2+}\right] a_{\mathrm{am}}}$

[am] is replaced by $a_{\mathrm{am}}=f_{\mathrm{am}}[\mathrm{am}]$, where $f_{\mathrm{am}}$ is the activity coefficient of methylamine. Distribution experiments (between water and chloroform) ${ }^{6}$ show qualitatively that the activity coefficient increases with the methylamine concentration. To obtain further information on this point the glass electrode deviation function in methylamine solutions $f_{\mathbf{g}}(\mathrm{am})$ has been determined with a Radiometer

Table 3. Estimation of $K_{\mathrm{OH}}^{\prime}$ by use of the molar extinction coefficients of three solutions with $\left[\mathrm{CH}_{3} \mathrm{NH}_{2}\right]=$ 5.72 and an isosbestic point at $540 \mathrm{~nm}$ (see Fig. $2(b)) .\left(\alpha_{z}-\alpha_{y}\right) /\left(\alpha_{z}-\alpha_{x}\right)=1 / 1.84=0.543 . K_{O H}^{\prime}=12.2$ with $K_{\mathrm{am}}=10^{-3}$, and 17.2 with $K_{\mathrm{am}}=0.5 \times 10^{-3}$.

\begin{tabular}{lccccccc}
\hline No. & 580 & 600 & 620 & 640 & 660 & 680 & Av. \\
\hline $14(x)$ & 78.5 & 86.0 & 89.4 & 88.3 & 84.0 & 77.5 & \\
& 6.1 & 8.3 & 9.9 & 9.8 & 9.6 & 9.4 & \\
& $(0.90)$ & $(0.88)$ & $(0.90)$ & $(0.78)$ & $(0.77)$ & $(0.79)$ & 0.84 \\
$15(y)$ & 72.4 & 77.7 & 79.5 & 78.5 & 74.4 & 68.1 & \\
& 6.8 & 9.4 & 11.0 & 12.5 & 12.5 & 11.9 & \\
& $(1)$ & $(1)$ & $(1)$ & $(1)$ & $(1)$ & $(1)$ & 1.00 \\
$16(z)$ & 65.6 & 68.3 & 68.5 & 66.0 & 61.9 & 56.2 & \\
\hline
\end{tabular}


Table 4. Comparison of the glass electrode deviation function in methylamine and in ammonia solutions. Measurements of methylamine solutions in $1 \mathrm{M} \mathrm{CH}_{3} \mathrm{NH}_{3} \mathrm{NO}_{3}$ against a standard $\mathrm{CH}_{3} \mathrm{NH}_{2}$-solution with $\mathrm{p}[\mathrm{am}]=0.934$ at $25^{\circ} \mathrm{C}$.

\begin{tabular}{llllllll}
\hline No. & {$[\mathrm{am}]$} & $\mathrm{p}[\mathrm{am}]$ & $E-E_{\mathrm{st}}$ & $\mathrm{p} g[\mathrm{am}]$ & $f_{\mathbf{g}}(\mathrm{am})$ & $f_{\mathbf{g}}\left(\mathrm{NH}_{3}\right)$ & $f_{\mathrm{NH}_{3}}$ \\
\hline 1 & 0.581 & +0.236 & 0.0415 & +0.232 & 1.01 & 1.00 & 1.01 \\
2 & 1.162 & -0.065 & 0.0590 & -0.064 & 1.00 & 1.00 & 1.02 \\
3 & 1.743 & -0.241 & 0.0701 & -0.252 & 1.02 & 1.03 & 1.05 \\
4 & 2.324 & -0.366 & 0.0781 & -0.387 & 1.05 & 1.06 & 1.10 \\
5 & 3.486 & -0.542 & 0.0903 & -0.594 & 1.13 & 1.12 & 1.18 \\
6 & 5.810 & -0.764 & 0.1088 & -0.907 & 1.39 & 1.30 & 1.38 \\
\hline
\end{tabular}

Table 5. Estimation of $K_{5}$ in $1 \mathrm{M} \mathrm{CH}_{3} \mathrm{NH}_{3} \mathrm{ClO}_{4}$ by use of the molar extinction coefficients of solutions 7 , 18 and 13 with an isosbestic point at $576 \mathrm{~nm}$ (see Fig. $2(d)) . K_{5}=0.13$ with $\left(\alpha_{z}-\alpha_{y}\right) /\left(\alpha_{z}-\alpha_{x}\right)=1.74 / 2.74=0.635$.

\begin{tabular}{llllcccccc}
\hline No. & {$[\mathrm{am}]$} & $f_{\mathrm{g}}(\mathrm{am})$ & $a_{\mathrm{am}}$ & 600 & 620 & 640 & 660 & 680 & Av. \\
\hline $13(z)$ & 5.72 & 1.38 & 7.89 & 97.4 & 101.0 & 99.0 & 93.7 & 86.1 & \\
& & & & 5.0 & 8.1 & 10.2 & 11.0 & 11.5 & \\
& & & & $(1.8)$ & $(1.9)$ & $(1.9)$ & $(1.6)$ & $(1.5)$ & 1.74 \\
$18(y)$ & 3.42 & 1.13 & 3.87 & 92.4 & 92.9 & 88.8 & 82.7 & 74.6 & \\
& & & & 2.8 & 4.3 & 5.3 & 6.8 & 8.4 & \\
& & & & $(1)$ & $(1)$ & $(1)$ & $(1)$ & $(1)$ & 1.00 \\
$7(x)$ & 2.26 & 1.05 & 2.37 & 89.6 & 88.6 & 83.5 & 75.9 & 67.2 & \\
\hline
\end{tabular}

Table 6. Estimation of $K_{5}$ in $0.5 \mathrm{M} \mathrm{CH}_{3} \mathrm{NH}_{3} \mathrm{NO}_{3}$ by use of the molar extinction coefficients of three solutions with $C_{\mathrm{C}_{u}}=0.0104 \mathrm{M}$ having a poorly defined isosbestic point at $\sim 565 \mathrm{~nm}$. $K_{5}=0.17$ with $\left(\alpha_{z}-\alpha_{y}\right) /\left(\alpha_{z}-\alpha_{x}\right)=1.55 / 2.55=0.608$.

\begin{tabular}{lccccccccc}
\hline$[\mathrm{am}]$ & $f_{\mathrm{g}}(\mathrm{am})$ & $a_{\mathrm{am}}$ & 620 & 640 & 660 & 680 & 700 & 720 & Av. \\
\hline 4.66 & 1.23 & 5.73 & 91.7 & 89.7 & 85.2 & 77.5 & 69.3 & 61.1 & \\
& & & 10.7 & 11.8 & 13.2 & 12.7 & 12.6 & 11.9 & \\
& & & $(1.6)$ & $(1.4)$ & $(1.6)$ & $(1.6)$ & $(1.6)$ & $(1.5)$ & 1.55 \\
2.31 & 1.05 & 2.43 & 81.0 & 77.9 & 72.0 & 64.8 & 56.7 & 49.2 & \\
& & & 6.9 & 8.3 & 8.4 & 7.8 & 7.9 & 7.8 & \\
& & & $(1)$ & $(1)$ & $(1)$ & $(1)$ & $(1)$ & $(1)$ & 1.00 \\
1.13 & 1.01 & 1.14 & 74.1 & 69.6 & 63.6 & 57.0 & 48.8 & 41.4 & \\
\hline
\end{tabular}

glass electrode (Type G 202 B). The results are shown in Table 4 and it will be seen that $f_{\mathrm{g}}(\mathrm{am})$ closely follows the analogous function determined in ammonia solutions ${ }^{7}$ and the activity coefficients for ammonia. An estimation of $K_{5}$ was performed using the results for solutions 7,18 and 13 in Table 1 (see Fig. 2) and data from three spectra measured in $0.5 \mathrm{M} \mathrm{CH}_{3} \mathrm{NH}_{3} \mathrm{NO}_{3}$. The results of the calculation using expression (5) with [L] replaced by $f_{\mathrm{g}}(\mathrm{am}) \times$ [am] $\sim a_{a m}$ and $K_{\text {ass }}$ by $K_{5}$ are shown in Tables 5 and 6 . The values obtained $\left(K_{5}=0.13\right.$ and 0.17$)$ agree satisfactorily with the indirectly-determined value. Comparing the values obtained in this paper $\left(K_{5} \equiv 0.15, K_{4, \mathrm{OH}} \equiv 16\right.$, and $K_{5, \mathrm{OH}} \equiv 110$ ) with those obtained for the ammonia system $\left(K_{5}=0.42\right.$, $K_{4, \mathrm{OH}}=9.3$, and $K_{5, \mathrm{OH}}=22.3$ ) it is seen that the 5 th 
amine molecule is bound somewhat more weakly, and the hydroxide ion somewhat more strongly, than is the case in the corresponding ammonia system. The fact that $K_{5}$ is smaller than in the ammonia system agrees well with the observation that the bis(ethylenediamine)copper(II) ion binds ammonia $(K=0.38)$ more strongly than butylamine $(K \equiv 0.17) .^{8}$ A comparison of the spectra of the individual methylamine and ammonia complexes is shown in Figs. 2(c) and (d).

The present study was begun by the senior author together with Liliana Ilcheva in 1975. Some preliminary measurements with Ilcheva were made of the UV-band and of the pentakis(methylamine) complex formation in methylammonium nitrate solutions. The experimental work was completed in 1978 together with B. V. Agarwala, who performed the greater part of the measuements.

Acknowledgement. The authors thank Dr. Martin Hancock for correcting the English manuscript.

\section{REFERENCES}

1. Bjerrum, J. and Agarwala, B. V. Acta Chem. Scand. A 34 (1980) 475.

2. Ilcheva, L. and Bjerrum, J. Acta Chem. Scand. A 30 (1976) 343.

3. Iitaka, Y., Shimizu, K. and Kwan, T. Acta Crystallogr. 20 (1966) 803.

4. Bjerrum, J. and Lamm, C. G. Acta Chem. Scand. $4(1950) 997$.

5. Näsänen, R. and Meriläinen, P. Suom. Kemistil. B 33 (1960) 149.

6. Felsing, W. A. and Ball, E. J. Am. Chem. Soc. 63 (1941) 2525.

7. Bjerrum, J. Metal Ammine Formation in Aqueous Solution, P. Haase and Son, 1941; Reprinted 1957.

8. Romano, V. and Bjerrum, J. Acta Chem. Scand. 24 (1970) 1551.

9. Bjerrum, J., Ballhausen, C. J. and Jørgensen, C. K. Acta Chem. Scand. 8 (1954) 1275.

10. Bjerrum, J. K. Dan. Vidensk. Selsk., Mat.-Fys. Medd. 11 (1932) No. 10.

Received June 6, 1980. 